\title{
Utility of AgroTech VNMKV Mobile App as Perceived by the User Farmers
}

\author{
H. Y. Pawar, P. S. Kapse* and S. G. Puri \\ Department of Extension Education, Vasantrao Naik Marathwada Krishi Vidyapeeth, \\ Parbhani 431402 (MS), India \\ *Corresponding author
}

A B S T R A C T

\begin{tabular}{|l|}
\hline Ke y w o r d s \\
Utility perception, \\
Mobile app, \\
Preference
\end{tabular}

The present study was undertaken with objectives to find out the utility of AgroTech VNMKV mobile App as perceived by user farmers and to study the preference of the user farmers for content in AgroTech VNMKV mobile App. A total of 120 respondents were selected as sample respondents for the study. Data revealed that the dimension of utility perception of the mobile app viz., Readability (100\%), Credibility (100\%), Accuracy (100\%), Clarity (100\%), Directness (100\%), and Factuality (100\%) had 100 UPI and had been ranked first, followed by Terminology $(99.05 \%)$ was ranked second. Whereas Understandability $(97.77 \%)$ ranked third position, followed by Timeliness $(97.22 \%)$, Practicability $(92.30 \%)$, Satisfaction $(90.83 \%)$, Brevity $(73.50 \%)$, Illustrativeness $(66.67 \%)$ and Coverage of subject matter $(47.50 \%)$. and were ranked IVth, Vth and VIth, VIIth, VIIIth and IXth, respectively. It also indicates that 47.50 per cent of coverage of subject matter in the app as per need of the user farmers. It has been further observed that the overall utility of AgroTech VNMKV mobile App was high as perceived by the user farmers. While subject matter viz., Varieties of Crops (4.966), Cultivation of crops (4.658), Dryland Agriculture (4.366), Soil Science (4.350), Modern Irrigation Methods (4.333), Profitable cropping method (4.308), Soil and Water Conservation (4.258), Pest Management (4.250) and Disease Management (4.133) were most preferred topics of the App by the user farmers, whereas Current Event - Blog link (3.950), Farm Equipment \& Machinery (3.950) Organic Farming (3.641), Subsidiary Occupations (3.625), Agricultural Engineering (3.475), Weed Management(3.441), GKMS Agro-advisory - Blog link (3.058), Watershed Development (2.375), Weather \& Soil of Marathwada (2.016), Security of Crop varieties \& Farmers Rights (1.991), Horticulture (1.941), Agro Forestry - Sag Cultivation (1.716), Extension Education (0.975), Home Science Technology (0.883), Agricultural Economic (0.525), Contacts $(0.041)$ were highly preferred by the user farmers.

\section{Introduction}

The use of Information and Communication Technology (ICT) to support the transmission of localized information and services working towards making farming socially, economically and environmentally sustainable, while contributing to the delivery of food for all - this comprises Digital Agriculture. This has also led to the rise and development of mobile apps which are helping existing government schemes, and other agriculture-based information to reach farmers in rural India.

This digital change is acting as a gamechanger for Indian agricultural conditions. An information gap between rural and urban areas has jeopardize the ability of rural people to realize their full potential and improve their 
economic, social and environmental conditions. These implications on the rural people were three fold such as loss of income, time and opportunity. Hence, efforts are to be made to empower farmers with the information. India possesses technical resources which can empower the farmers with the information they need and in turn help them improve their productivity and livelihood.

Smart phones have penetrated in almost all the area where people carry out their everyday activities, and perform tasks that are normally run on personal computers. Also, mobile literacy is higher than computer literacy, even though mobile devices might have inconvenient user interfaces. Hence mobile applications are good option for transmitting information to the people in villages and rural areas.

Today farmers are receiving diverse information about farming like seeds, crop selection, crop processes, weather, fertilizer, pesticides from various resources which are distributed on many different locations according to its origin, its processors, producers etc. It is true that the information is available by means of several applications, videos, images, but the problem lies in the fact that the information is not available at the same platform - a system which covers all the important information about all the domains of agriculture and available at their location. (Sunidhi Sharma et al., 2018).

Mobile apps in the arena of agriculture can be the best option to increase agriculture production. The inventions in technology in agriculture domain are not getting to the farmers; because of either most of them are illiterates or due to unawareness of the location from where they can have information. Therefore, utmost of the farmers is being failed in acquisition of the possible production rate. It is required to develop a system from where the required information is available to the farmer directly from scientific community. New opportunities are shaped by smart phone technology for farmers. Farmers are capable with a low cost smart phone and the particular software to gain facilities which couldn't available on their hands before. In the days of financial crisis, farming is becoming more and more vigorous and much more important to be completed efficiently during the time period.

The rapid expansion and use of mobile apps has created a new field in the digital ecosystem, which consists of thousands of developers, popular software platforms and millions of users. Mobile apps are typically available through native distribution platforms, so-called App stores that are operated by the owners of the mobile operating system. Mobile apps increasingly constitute complete ecosystems to support business, such as entertainment, health, tourism, shopping, education and farming. The mobile agricultural apps show significant potential for the modernization of the agriculture.

There are varieties of mobile applications, utilized over the globe for different segments, including farming, but here the usage is still is limited. We have elaborated various agricultural mobile applications which potentially can be used in farming and allied activities as indicated by their source and usage. In India, there are enormous opportunities for utilizing the smart phones as a part of agribusiness improvement. Its utilization is vital for quick growth and easy access to information to Indian agriculturists, farmers and growers. Vasantrao Naik Marathwada Krishi Vidyapeeth, Parbhani have developed eleven mobile apps related to the different technologies, AgroTech VNMKV is one of them. AgroTech VNMKV 
mobile application is launched in the month of 29th May, 2017 by the University. This mobile application gives complete details about farming and its technologies recommended by the University particularly for the farmers of Marathwada region in local language i.e. Marathi. The App provide information about cultivation of important crops viz., Kharif crop, Rabi crop, fruit crops, vegetable crops etc. Farmer get information about different varieties related to cereals, pulses, oil seed and commercial crops.

Information about control measures of pest and disease is also included in the app. Information about watershed development program, modern irrigation techniques, soil and water conservation, allied enterprises, weather and soil report in Marathawada region, protection of plant varieties and farmers right are also available in this mobile app. It also deals with home science, extension education and agricultural economics. The present study was undertaken with objectives to find out the utility of AgroTech VNMKV mobile App as perceived by user farmers and to study the preference of the user farmers for content in AgroTech VNMKV mobile App.

\section{Materials and Methods}

The study was conducted purposively in the Marathwada region of Maharashtra State, for the reason that AgroTech VNMKV mobile App is primarily meant for the region. The study was conducted purposively in the Parbhani district, as headquarter of the University. Ten villages were randomly selected from the Parbhani and Manwath taluka of Parbhani district. List of user farmers of AgroTech VNMKV mobile App was collected from university authorities, twelve user farmers of the mobile App were selected randomly from each village. Thus a total of 120 respondents were selected as sample respondents for the study. Ex-post facto research approach was used for the present study and one shot case study research design was used. The variables which were perceived as relevant to the study selected.

The term utility perception is defined as the degree to which an AgroTech VNMKV App is perceived as useful to gain required technological information. The total of scores given by an individual to each item or component was taken as his overall perceived utility score. The respondent were classified as low, medium and high category on the basis of overall perceived utility by using the mean \pm S.D. formula.

\section{Utility perception index (UPI)}

Utility perception scale developed by Jondhale (1989) was used with slight modification in the study. Fourteen components viz., readability, credibility, timeliness, understandability, practicability, accuracy of information, coverage of subject matter, clarity, terminology, brevity, directness, illustrativeness, factuality and satisfaction in reading were included in the scale to measure utility perception of AgroTech VNMKV mobile App related to information content. The maximum score that the respondents could get on all of the 14 items was 67 and the minimum was 13 . Utility perception index of each component calculated by obtained for component and maximum score for component utility perception index was calculated by using following formula;

$$
\text { UPI }=\frac{\text { Sum of score obtained for component }}{\text { Maximum possible score for component }} \times 100
$$

For determining the preference of readers for various subject matters a special procedure was followed. There were twenty six (26) 
topics or subject matter areas appeared in the mobile app. Relative preferences available to the respondents for each item and the scores given to relative preferences are $0,1,2,3,4$, and 5 to the responses viz., never, very less, less, moderate, high and very high, respectively.

The mean score for each subject matter area was taken as the overall performance of the item. The mean score of each subject matter were computed by using the following formula;

Mean score of subject matter $=\frac{\text { Total score obtained by the subject matter area }}{\text { Total number of respondents }}$

The data were collected through personal interview method and were analysed with the help of frequency, percentage, mean and standard deviation.

\section{Results and Discussion}

\section{Utility of agrotech VNMKV mobile app as perceived by the user farmers}

The utility of AgroTech VNMKV mobile App about 14 sub-component i.e. dimensions as perceived by the user farmers is presented in Table 1.

It was observed from Table 1 that the dimension of utility perception of the mobile app viz., Readability (100\%), Credibility (100\%), Accuracy (100\%), Clarity (100\%), Directness (100\%), and Factuality (100\%) had 100 UPI and had been ranked first, followed by Terminology (99.05\%) was ranked second. Whereas Understandability $(97.77 \%)$ ranked third position, followed by Timeliness (97.22\%), Practicability (92.30\%), Satisfaction (90.83\%), Brevity $(73.50 \%)$, Illustrativeness $(66.67 \%)$ and Coverage of subject matter $(47.50 \%)$. and were ranked IVth, Vth and VIth, VIIth, VIIIth and IXth, respectively. It also indicates that 47.50 per cent of coverage of subject matter in the app as per need of the user farmers.

Thus, it could be concluded that overall utility perception of AgroTech VNMKV Mobile App by the users seems high as per their distribution on utility perception categories. However the utility perception index (UPI) components like Readability, Credibility, Accuracy of information, Clarity, Directness and Factuality was 100. This may be because of information provided by App is readable, credible, with the accuracy, clear, directness and imaginative to user. Other component such as Terminology, Timeliness, Understandability, Practicability, and Brevity were high. Utility perception index of mobile App with regards to Illustritativeness component was 66.67 per cent. It means that information in the app should be provided with more relevant pictures, photographs, tables, numeric data etc. as perceived by user farmers for more utility of the app. Similarly, Utility perception index of the mobile App with respective Coverage of subject matter was 47.50 per cent, this might be due to all needed information or subject matters are not included as per need of the user farmers. This means there is a scope for the improvement.

\section{Overall utility of agrotech VNMKV mobile app as perceived by the users}

The present investigation aimed at assessing the overall utility of AgroTech VNMKV mobile App as perceived by the users. Overall utility of AgroTech VNMKV mobile App as perceived by the users was carried out and data are presented in Table 2.

It has been observed that the majority of respondent $(65.00 \%)$ had high utility perception, followed by medium quality perception $(33.33 \%)$ and low utility perception $(1.67 \%)$. Thus the overall utility of 
AgroTech VNMKV mobile App was high as perceived by the user farmers.

Preference of the users for content in agrotech VNMKV mobile app

The AgroTech VNMKV mobile App contained 26 topic or subject matter areas. Based on mean preference value, 26 subject matters are ranked and given in Table 3 . It has been observed from Table 3 that Varieties of Crops (4.966), Cultivation of crops (4.658), Dryland Agriculture (4.366), Soil Science (4.350), Modern Irrigation Methods (4.333), Profitable cropping method (4.308), Soil and Water Conservation (4.258), Pest Management (4.250) and Disease Management (4.133) were most preferred topics of the App by the user farmers, whereas Current Event - Blog link (3.950), Farm Equipment \& Machinery (3.950) Organic Farming (3.641), Subsidiary Occupations (3.625), Agricultural Engineering (3.475), Weed
Management(3.441), GKMS Agro-advisory Blog link (3.058), Watershed Development (2.375), Weather \& Soil of Marathwada (2.016), Security of Crop varieties \& Farmers Rights (1.991), Horticulture (1.941), Agro Forestry - Sag Cultivation (1.716), Extension Education (0.975), Home Science Technology (0.883), Agricultural Economic (0.525), Contacts (0.041).

It is further observed that Content in AgroTech VNMKV Mobile App like Varieties of Crops, Cultivation of crops, Profitable cropping method, Dryland Agriculture, Modern Irrigation Methods, Pest Management, Soil Science, Disease Management, Soil and Water Conservation was highly preferred by users. These contents in App are important component required for each and every aspects of agriculture production these topics are major contributing factors for increasing agricultural production in the study areas.

Table.1 Utility of AgroTech VNMKV mobile App about various dimensions as perceived by the user farmers

\begin{tabular}{|c|l|c|c|}
\hline S. No. & Category / Parameters & Utility perception index & Ranks \\
\hline $\mathbf{1}$ & Readability & 100.00 & I \\
\hline $\mathbf{2}$ & Credibility & 100.00 & I \\
\hline $\mathbf{3}$ & Timeliness & 97.22 & IV \\
\hline $\mathbf{4}$ & Understandability & 97.77 & III \\
\hline $\mathbf{5}$ & Practicability & 92.30 & V \\
\hline $\mathbf{6}$ & Accuracy of information & 100.00 & I \\
\hline $\mathbf{7}$ & Coverage of subject matter & 47.50 & IX \\
\hline $\mathbf{8}$ & Clarity & 100.00 & I \\
\hline $\mathbf{9}$ & Terminology & 99.50 & II \\
\hline $\mathbf{1 0}$ & Brevity & 73.75 & VII \\
\hline $\mathbf{1 1}$ & Directness & 100.00 & I \\
\hline $\mathbf{1 2}$ & Illustrativeness & 66.67 & VIII \\
\hline $\mathbf{1 3}$ & Factuality & 100.00 & I \\
\hline $\mathbf{1 4}$ & Satisfaction & $\mathbf{9 0 . 8 3}$ & VI \\
\hline
\end{tabular}


Table.2 Overall utility of AgroTech VNMKV mobile App as perceived by the users $(\mathrm{N}=120)$

\begin{tabular}{|c|l|c|c|}
\hline S. No. & Utility perception & Frequency & Percentage \\
\hline $\mathbf{1}$ & Low (Up to 80) & 02 & $\mathbf{1 . 6 7}$ \\
\hline $\mathbf{2}$ & Medium (81-89) & 40 & $\mathbf{3 3 . 3 3}$ \\
\hline $\mathbf{3}$ & High $(\mathbf{9 0}$ and above) & $\mathbf{7 8}$ & $\mathbf{6 5 . 0 0}$ \\
\hline
\end{tabular}

Table.3 Preference of the user farmers for the content (subject matter) in AgroTech VNMKV mobileApp ( $\mathrm{N}=120)$

\begin{tabular}{|c|c|c|c|}
\hline $\mathbf{S}$ & $\begin{array}{c}\text { Content / subject matter in AgroTech } \\
\text { VNMKV mobile app }\end{array}$ & $\begin{array}{c}\text { Mean } \\
\text { Preference }\end{array}$ & $\begin{array}{l}\text { Preference } \\
\text { order }\end{array}$ \\
\hline 1 & Varieties of Crops & 4.966 & I \\
\hline 2 & Cultivation of Crops & 4.658 & II \\
\hline 3 & Profitable Cropping Methods & 4.308 & III \\
\hline 4 & Dryland Agriculture & 4.366 & IV \\
\hline 5 & Modern Irrigation Methods & 4.333 & V \\
\hline 6 & Pest Management & 4.250 & VI \\
\hline 7 & Soil Science & 4.350 & VII \\
\hline 8 & Disease Management & 4.133 & VIII \\
\hline 9 & Soil \& Water Conservation & 4.258 & IX \\
\hline 10 & Current Event - Blog link & 3.950 & $\mathbf{X}$ \\
\hline 11 & Farm Equipment \& Machinery & 3.950 & XI \\
\hline 12 & Current Recommendations of the University & 3.408 & XII \\
\hline 13 & Organic Farming & 3.641 & XIII \\
\hline 14 & Subsidiary Occupations & 3.625 & XIV \\
\hline 15 & Weed Management & 3.441 & $\mathbf{X V}$ \\
\hline 16 & Agricultural Engineering & 3.475 & XVI \\
\hline 17 & $\begin{array}{l}\text { GKMS Agro-advisory - Blog link } \\
\text { (Gramin Krushi Mosum Seva Blog link) }\end{array}$ & 3.058 & XVII \\
\hline 18 & Watershed Development & 2.375 & XVIII \\
\hline 19 & Weather \& Soil of Marathwada & 2.016 & XIX \\
\hline 20 & Security of Crop varieties \& Farmers Rights & 1.991 & $\mathbf{X X}$ \\
\hline 21 & Horticulture & 1.941 & XXI \\
\hline 22 & Agro Forestry - Sag Cultivation & 1.716 & XXII \\
\hline 23 & Extension Education & 0.975 & XXIII \\
\hline 24 & Home Science Technology & 0.883 & XXIV \\
\hline 25 & Agricultural Economic & 0.525 & XXV \\
\hline 26 & Contacts & 0.041 & XXVI \\
\hline
\end{tabular}

Profitable cropping method, dryland agriculture, modern irrigation method and soil and water conservation help to provide guidance about proper utilization of natural resources under climate change situation. Thus, these subject matter of the app was also preferred more by the user farmers. Some content in App like Current Event - Blog link, Farm Equipment and Machinery, Current Recommendations of the University, Organic Farming, Subsidiary Occupations, Weed Management, Agricultural Engineering and 
GKMS Agro-advisory - Blog link were moderately preferred by users. These findings were in line with the finding of Mangal Shinde (2016) and Teza (2016).

\section{References}

Jondhale, S.G. 1988. Content analysis of farm magazines - An exploratory study. Ph.D. (Agri.) Thesis, MKV, Parbhani.

Mangal Shinde, 2016. Utility perception of VNMKV calendar by the readers. M.Sc. (Agri.) Thesis, VNMKV, Parbhani.
Sunidhi Sharma, D.K. Sharma and Supriti Sharma, 2018. Overview of mobile android agriculture applications. International Reference Journal of Engineering and Technology, 5 (8): 225-231.

Teza, J., 2016. Mobile Apps as an extension services delivery tool among the livestock farmers: An exploratory study. Ph.D. (Agri.) Thesis, P.V. Narsimha Rao Telangana Veterinary University, Hyderabad, Telangana.

\section{How to cite this article:}

Pawar, H. Y., P. S. Kapse and Puri, S. G. 2020. Utility of AgroTech VNMKV Mobile App as Perceived by the User Farmers. Int.J.Curr.Microbiol.App.Sci. 9(04): 1280-1286.

doi: https://doi.org/10.20546/ijcmas.2020.904.150 